\title{
Aspectos toxicológicos e legislação internacional referente ao uso do mercúrio
}

Toxicological aspects and international law in reference to the use of mercury

Aspectos toxicológicos y el derecho internacional en referencia a la utilización de mercurio

\author{
Yasmim Priscila Loezer \\ Graduada, UNIP, Brasil \\ yasmim.loezer@hotmail.com \\ Fernanda Silva Graciani \\ Doutora, UFGD/Fundect, Brasil \\ fergraciani@uol.com.br
}

Gabriel Luis Bonora Vidrih Ferreira

Doutor, UEMS, Brasil gvidrih@uems.br 


\section{INTRODUÇÃO}

Caracterizado como um metal pesado, o mercúrio é apontado como um poluente ambiental de elevado risco à saúde humana. Este pode ser encontrado na natureza em três formas químicas: mercúrio metálico ou elementar $\left(\mathrm{Hg}^{0}\right)$, sais inorgânicos de mercúrio quando complexados com cloro e enxofre, e mercúrio orgânico (metilmercúrio, dimetilmercúrio e fenilmercúrio), cada qual com diferentes características de biodisponibilidade e toxicidade. Apesar de todas as formas serem consideradas tóxicas, os compostos orgânicos são os que causam maior preocupação em decorrência de sua fácil penetração por membranas biológicas (CARDOSO et al, 2001).

Um dos motivos que colaboram para que o $\mathrm{Hg}$ seja considerado um contaminante de elevada toxicidade consiste em sua característica peculiar de distribuição no meio ambiente, denominada Ciclo Biogeoquímico do Mercúrio, que acarreta a possibilidade de afetação a amplas áreas distantes de sua fonte de emissão com o surgimento de efeitos mesmo após um longo período depois de cessada a exposição (OGA et al, 2008).

Atualmente o controle do mercúrio surge como uma preocupação mundial em consequência de sua alta toxicidade e persistência na atmosfera.

\section{OBJETIVOS}

O presente trabalho tem como objetivo geral identificar o perfil toxicológico do mercúrio e sua recente regulação internacional, destacando os seus potenciais impactos à saúde ambiental e humana e a iniciativa trazida pela Convenção de Minamata.

São objetivos específicos do trabalho:

Caracterizar o mercúrio como significativa fonte de poluição ambiental;

Apontar os efeitos e sintomas decorrentes da intoxicação por mercúrio;

Indicar o mercúrio como problema ambiental global em razão da possibilidade de afetação a áreas distantes de sua fonte de emissão;

Destacar a Convenção de Minamata com instrumento internacional destinado a controlar as emissões de mercúrio.

\section{METODOLOGIA}

Para subsidiar o estudo, utilizou-se das técnicas de pesquisa documental e pesquisa bibliográfica, com análise de trabalhos técnicos e científicos, além de dispositivos legais internacionais que se relacionam com a temática. 


\section{RESULTADO (S)}

\subsection{O MERCÚRIO COMO FONTE DE POLUIÇÃO}

Apesar de ser considerado um metal extremamente tóxico, a produção mundial atual do mercúrio e seus compostos é estimada em 10.000 toneladas por ano, sendo utilizado nas mais diversas áreas, podendo ser empregado na agricultura, como fungicida; como anti-séptico na medicina; na indústria química como catalisador no preparo de cloreto de vinila, na fabricação de termômetros, termostatos, indústrias de tintas, de lâmpadas e de cloro-soda. É também bastante empregado na indústria de explosivos, na mineração e na odontologia. Atualmente, o mercúrio utilizado em amálgama dentário está sendo substituído pelo bismuto que exerce características semelhantes (CARDOSO et al, 2001).

Há um número crescente de estudos que confirmam que a contaminação pelo mercúrio tem sido mais frequente do que aquelas relativas a outros metais. A explicação para este fato se deve ao transporte atmosférico e sua persistência no meio ambiente.

Dependendo do tipo de fonte produtora, a forma do mercúrio apresenta variações. Em grande parte das emissões aéreas, o metal encontra-se em sua forma gasosa elementar, que é carregado globalmente para locais distantes das fontes de emissão. 0 tempo de persistência na atmosfera é de 1 a 2 anos, depositando-se em corpos d'água ou solo em até $1000 \mathrm{~km}$ de distância (LACERDA e MALM; 2008).

Desde tempos remotos há registros de poluições ambientais referentes ao mercúrio. Porém, a partir do século XIX, com a demanda industrial, este problema tem se elevado, alcançando proporções alarmantes (MÖLLERKE, 2002).

No contexto de intoxicações em larga escala, destaca-se o desastre ocorrido por volta de 1953 na Baía de Minamata, sudoeste do Japão. Uma fábrica produtora de compostos orgânicos utilizava o mercúrio metálico como agente catalítico na produção de acetaldeído e cloreto de vinila, lançando metilmercúrio nos efluentes. Estes compostos se dispersavam e sedimentavam no mar Shiranui, sendo absorvidos pelo plâncton e outros microrganismos, dando inicio à contaminação da cadeia alimentar aquática (OGA et al, 2008).

\subsection{EFEITOS E SINTOMAS DECORRENTES DA INTOXICAÇÃO}

O mercúrio e seus compostos podem provocar diversos problemas à saúde humana, tanto em decorrência de exposição aguda ou crônica, agindo por sua afinidade com grupamentos sulfidrilas (SH) presentes em sistemas enzimáticos, em órgãos e tecidos distintos. Os efeitos tóxicos variam de acordo com a forma de ocorrência e exposição, podendo apresentar efeitos sobre o sistema nervoso, renal, reprodutor, imunológico, cardiovascular, atividade motora e efeitos genotóxicos (OGA et al, 2008).

A intoxicação aguda pode ser gerada de maneira acidental, pelo consumo, aspiração ou contato dérmico em grandes quantidades. Os principais órgãos afetados após intoxicação aguda são os rins, pulmões e intestino (LANGFORD e FERNER, 1999). 
As lesões renais acarretadas pelo mercúrio são progressivas e estão limitadas em grande parte ao epitélio tubular, especialmente o túbulo proximal. Contudo, os glomérulos também são lesados, em casos de exposição prolongada. A nefrotoxidade observada, em especial pela presença dos sais inorgânicos de mercúrio, deve-se à interação direta do metal com as células tubulares renais e sua concentração inerente dentro delas (PERLINGUEIRO, 1993).

Também tem sido constatado que vapores de mercúrio, em altas concentrações, geram lesões pulmonares como irritação traqueo-branquial, podendo progredir de edema lesional à fibrose intersticial difusa. Tais alterações parecem estar associadas com a capacidade do íon mercúrico em inativar, a nível celular, enzimas como a superóxido dismutase (SOD) resultando em menor eliminação de radicais livres, os quais passam então a induzir lesões pulmonares (PERLINGUEIRO, 1993).

Alem de complicações renais e respiratórias, a exposição aguda também resulta em problemas visuais, mentais e sintomas como salivação, fadiga, fraqueza, tremores e febre.

A exposição crônica por metil mercúrio $(\mathrm{MeHg})$, pode provocar danos ao sistema nervoso central, afetando principalmente áreas especificas do cérebro como lobos temporais e cerebelo (OGA et al, 2008). Os principais sintomas observados são: ataxia (perda dos movimentos voluntários), disartria (problema na articulação de palavras), parestesia (perda de sensibilidade), diminuição do campo visual, dificuldade auditiva, mudança de personalidade, tremores e perda de memória. Contaminações severas podem causar cegueira, coma e morte (MÖLLERKE, 2002).

\subsection{CONVENÇÃO DE MINAMATA}

Em resposta à percepção de que a poluição por mercúrio é um problema global e que nenhum país pode resolver este problema sozinho ou de forma isolada, em outubro de 2013, em Kunamoto, no Japão, representantes de cerca de 140 países assinaram um tratado, concordando, por consenso, que é necessário tomar medidas compulsórias e voluntárias para controlar as emissões de mercúrio proveniente de várias fontes. Este tratado foi assinado em uma convenção internacional para controlar as emissões de mercúrio, nomeada Convenção de Minamata sobre Mercúrio (KESSLER, 2013).

De uma maneira geral, a Convenção de Minamata tem como foco o resguardo da saúde humana e do meio ambiente e estabelece medidas relacionadas: a) ao controle de fontes e comércio de mercúrio; b) diretrizes para a redução de emissões e liberações ao meio ambiente; c) políticas específicas voltadas para certos produtos ou processos industriais; d) elaboração de planos nacionais quanto ao mercúrio utilizado em garimpo; e) intercâmbio e cooperação dos estados para a implementação das disposições.

\section{CONSIDERAÇÕES FINAIS}

A partir do estudo realizado conclui-se que o mercúrio é um poluente ambiental de elevado risco à saúde humana. Por ainda ser usado em diversos processos industriais e extrativistas, 
intoxicações oriundas da exposição ao $\mathrm{Hg}$ e seus compostos são frequentes no mundo todo. Diante do exposto, torna-se imprescindível a tomada de decisões sobre a diminuição do uso deste metal.

A Convenção de Minamata reconhece que a problemática ambiental trazida pelo mercúrio constitui matéria que enseja um tratamento cooperativo e integrado entre os estados de modo a se conferir efetividade para as políticas de prevenção à sua contaminação.

\section{REFERÊNCIAS BIBLIOGRÁFICAS}

CARDOSO, P. C. S. et al. Efeitos biológicos do mercúrio e seus derivados em seres humanos: uma revisão bibliográfica. Revista Paraense de Medicina. v.15, n. 4, 2001, p.51-58.

LACERDA, L. D.; MALM, O. Contaminação por mercúrio em ecossistemas aquáticos: uma análise das áreas críticas. Estudos Avançados. v.22, n. 63, 2008, p.173-190.

LANGFORD, N.J.; FERNER, R.E. Toxicity of mercury. Journal of Human Hypertension. V.13, n.10, 1999, p.651-656.

MÖLLERKE, R.O. Mercúrio, Arsênio e Colimetria como indicadores biológicos, na avaliação da qualidade do pescado artesanal do Lago Guaíba Porto Alegre, Estado do Rio Grande do Sul, Brasil. 2002. Tese (Faculdade de Medicina Veterinária) - Universidade Federal do Rio Grande do Sul, 2002.

OGA, S. et al. Fundamentos da Toxicologia. 3.ed. São Paulo: Atheneu, 2008.

PERLINGUEIRO, R.C.R. Função celular em indivíduos com exposição ocupacional ao mercúrio. 1993. Dissertação (Faculdade de Ciências Médicas) - Universidade Estadual de Campinas, 1993.

KESSLER, R. The Minamata Convention on Mercury: A First Step Toward Protecting Future Generations. Environmental Health Perspectives. v.121, n.10, 2013, p.304-308. 